\title{
Adsorption study of congo red dye with ZSM-5 directly synthesized from bangka kaolin withouth organic template
}

\author{
Ani Iryani ${ }^{a}$, Moh. Mualliful IImi ${ }^{b}$, Djoko Hartanto ${ }^{b},{ }^{*}$ \\ ${ }^{a}$ Department of Cemistry, Faculty of Mathematics and Natural Sciences, Pakuan University, Bogor \\ ${ }^{b}$ Department of Cemistry, Faculty of Sciences, Institut Teknologi Sepuluh Nopember, Surabaya \\ * Corresponding author: djokohar@its.ac.id
}

\section{Article history}

Received 22 November 2017

Accepted 20 December 2017

\begin{abstract}
ZSM-5's adsorption study of kaolin Bangka without organic template using congo red with initial concentration of $50-250 \mathrm{mg} / \mathrm{L}$ with variation of contact time of $40-180$ minutes. The results of the adsorption of Congo Red (CR) dye at $30^{\circ} \mathrm{C}-50^{\circ} \mathrm{C}$ with $\mathrm{pH} 7$, the increase in contact time causes the dye to decrease significantly. In addition, an increase in adsorption rate at first step then slows down as it approaches to the equilibrium point. The experimental results using each temperature variation, showing the equilibrium time of the adsorption process at contact time of 100 minutes. Four isotherm adsorption models were used to analyze and measure the results of experimental data adsorption. The ZSM-5 adsorption capacity of Bangka kaolin is exhibited for the reds of Congo isotherm adsorption. The results of isotherm adsorption studies on three temperatures showed the fitting into Langmuir isotherms adsorption type which means the adsroption occured physically monolayer, the kinetics of adsorption clearly follows the first-pseudo-order reaction kinetics with higher $\mathrm{R}^{2}$ closes to 1 . The adsorption thermodynamics analysis show that the adsorption chategorized as exthormic reaction (negative value of $\Delta H^{\circ}$ ), this conclusion is supported by adsortion capacity data in 180 min contact times which demostrate that the increasing adorption temperature decreasing amount adsorbate being adsorbed. The $\Delta G^{\circ}$ (Gibb's Energy) of adsorption are negative in several temperature which demonstrates that the adsroption are spontanously occured in ech temperature. The adsorption study can be used as a reference for ZSM-5 adsorption optimization.
\end{abstract}

Keywords: Bangka kaolin, ZSM-5, congo red, isotherm adsorption

\section{INTRODUCTION}

In recent years, the legal requirements for hazardous industrial waste discharged into waterways have been increasing rapidly. Consequently, the use of conventional techniques such as tertiary care processes becomes less efficient to produce less harmful aqueous wastes and meet the requirements of the new law. This is due to the high stability of the removed material resistant to the low-oxidizing agent and also its resistance to aerobic digestion. For example, many dyes used in the textile industry and elsewhere are very difficult to remove from aqueous waste by conventional waste treatment methods. For this reason, efficient new techniques are now urgently needed to reduce the dye content of aqueous waste associated with the textile industry to a legally acceptable level.

In developing countries, the textile industry plays an important role in economic development, but the textile industry also creates serious environmental problems, especially waste from yarn or cloth dyeing processes. Wastewater contains colored dye residue compounds and various chemical additives used in the staining process [1]. This waste is very dangerous for the environment especially for aquatic life if released through inadequate care [2], due to water solubility and stability with low to high concentrations.

Some researchers have reported extensively that long lasting dissolved organic deys contaminants can be efficiently removed by adsorption techniques $[1,2,3,4,5,6,7,8,9]$. This technique can produce waste-free water without odor, thus reducing the consumption of water for waste processing in this industrial sector. In addition, the operation of this unit offers flexibility in design.
Adsorption involving activated carbon has long been regarded as a conventional treatment process that can remove a multitude of pollutants. However, the high cost of activated carbon has restricted its use, particularly in developing countries. This is the reason why many investigators have studied the feasibility of using cheap, commercially available materials as removal agents for dyes $[6,4,10]$.

ZSM-5 as an adsorbent has long been known and easy to use [11], the availability of ZSM-5 can be improved by converting from the kaolin mineral as the raw material to ZSM-5. Hartanto et al. [12] reported how to synthesis ZSM-5 of Bangka Kaolin without treatment and without template.

In this paper, how is the adsorption character of textile on ZSM-5from-kaolin had been studied, especially the capacity and the adsorption mechanism on ZSM-5-from-Bangka-kaolin including the isotherm adsorption, adsorption kinetics and adsorption thermodynamics. Due to the many types of dyes used in the textile industry, in this study selected dyes commonly used in the textile industry, namely Congo Red. This data is expected to be used to help simplify the planning

\section{EXPERIMENTAL}

\section{Materials}

ZSM-5 which synthesized directly from Bangka kaolin without pretreatment and without using organic template. The dyes materials were used in this experiments are Congo red (CR), has chemical 
formula weight 696.65 and $\lambda \max 498 \mathrm{~nm}$. Aquades was used as a solvent.

\section{Adsorbent preparation}

ZSM-5 was synthesized directly from Bangka kaolin without pretreatment and without using organic template. The synthesis procedure of ZSM-5 was adopted from Hartanto, D., et al [12], taking the recipe for $\mathrm{Si} / \mathrm{Al}$ molar ratio was 60 .

\section{Adsorbate preparation}

The dyes materials were used in this experiments are Congo red (CR), has chemical formula weight 696.65 and $\lambda_{\max } 498 \mathrm{~nm}$. The stock dyes solution have concentration are $500 \mathrm{mg} / \mathrm{L}$, that was prepared by dissolving $0.5 \mathrm{~g}$ of dye powder in $1000 \mathrm{ml}$ of distilled water. Different dilutions ware made any ranging from 60 to $250 \mathrm{mg} / \mathrm{L}$, were then prepared using distilled water.

The properties of CR dye used are listed in Table 1, while the chemical structure of CR dye is shown in Figure 1.

Tabel 1. Physicochemical characteritics of Congo red dye [13].

\begin{tabular}{|c|c|}
\hline CAS No & $573-58-0$ \\
\hline CA Index name & $\begin{array}{l}\text { 1-Naphthalenesulfonic acid, 3,3'- } \\
\text { [(1,1'-biphenyl)-4,4'-diylbis(2,1- } \\
\text { diazenediyl)]bis[4 amino-,sodium } \\
\text { salt }(1: 2)]\end{array}$ \\
\hline Molecular formula & $\mathrm{C}_{32} \mathrm{H}_{22} \mathrm{~N}_{6} \mathrm{Na}_{2} \mathrm{O}_{6} \mathrm{~S}_{2}$ \\
\hline Molecular weight & $696.66 \mathrm{~g} \mathrm{~mol}^{-1}$ \\
\hline Physical form & Brownish-red powder \\
\hline Molecular surface area & $557.6 \AA^{2}$ \\
\hline Solubility & $\begin{array}{l}\text { soluble in water, ethanol; very } \\
\text { slightly soluble in acetone; } \\
\text { practically insoluble in ether, xylene }\end{array}$ \\
\hline Melting point & $>360^{\circ} \mathrm{C}$ \\
\hline pH range & $3.0-5.0$ \\
\hline Colour & Blue $(\mathrm{pH} 3.0)$ to red $(\mathrm{pH} 5.0)$ \\
\hline PKa & $4.1 ; 3.0$ \\
\hline Absorption wavelength ( $\lambda \max )$ & $497 \mathrm{~nm}$ \\
\hline
\end{tabular}

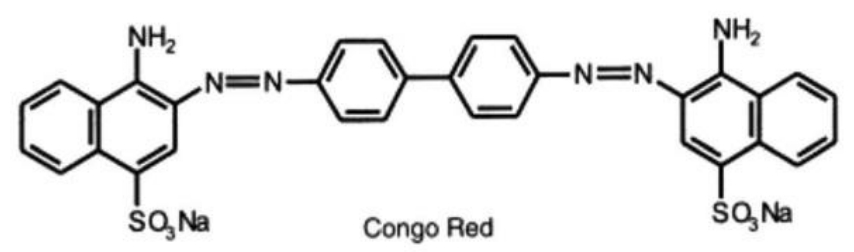

Fig. 1 Chemical Structure of Congo Red [13].

\section{Adsorption experiments}

Adsorption experiments were conducted by a batch method. A series of polypropylene centrifuge tube containing $0.10 \mathrm{~g}$ of ZSM-5 with $50 \mathrm{~mL}$ of dye solution $(0-100 \mathrm{mg} / \mathrm{L})$ were prepared. The tube was then shaken with a shaker at $150 \mathrm{rpm}$ at any temperature $(15,30,40$ and $50{ }^{\circ} \mathrm{C}$ ) for 16 hours to reach the equilibrium and followed by centrifugation at $2900 \mathrm{rpm}$ for 15 minutes for sparation. Filtration was carried out to separate the filtrated and residue of adsorbents with 0.1 $\mu \mathrm{m}$ of membrane filter (Millipore, Japan). The absorbance of filtered samples ware measured at peak wavelengh of dyes with UV-2550 UVVisible Spectrophotometer. below :

The adsorption capacity was calculated by following the equation

$$
Q_{e}=\left(C_{0}-C_{e}\right) / C_{0} \times 100 \%
$$

where : $\mathrm{q}_{\mathrm{e}}$ is the adsorption capacity, the dyes uptake by a unit weight of adsorbent $(\mathrm{mg} / \mathrm{g}), \mathrm{C}_{\mathrm{o}}$ is the initial concentration of dye $(\mathrm{mg} / \mathrm{L}), \mathrm{C}_{\mathrm{e}}$ is the residual concentration of dye $(\mathrm{mg} / \mathrm{L}), \mathrm{V}$ is the volume of solution (L) and $\mathrm{m}$ is the weight of adsorbent ( $\mathrm{g}$ ).

\section{Adsorption Isotherm}

The relationship between the amount of adsorbate absorbed by the concentration of adsorbate in solution at equilibrium and temperature conditions can be expressed by adsorption isotherm.

In isothermal adsorption, in that circumstance the amount of adsorbate (molecule adsorbed) is a function of pressure (if its molecule in the form of a gas) or as a function of concentration at a constant temperature state.

The isotherm adsorption process can be understood through isotherms produced between the contact time (20-180 minutes) and the amount of adsorbate absorbed by the adsorbent mass unit at constant temperature $(298 \mathrm{~K})$. In the results of this study used experimental data analysis using Langmuir isotherm adsorption model, Freundlich, Tempkin and Dubinin-Radushkevich (D-R).

The applicability and suitability of the isotherm equation to the equilibrium data were compared using the values of the correlation coefficients, $\mathrm{R}^{2}$.

\section{Langmuir adsorption isotherm}

Langmuir Adsorption Isotherm is based on several assumptions, ie, adsorption occurs only on a single layer (monolayer), the adsorption heat is independent of surface closure, and all sites and surfaces are homogeneous.

The Langmuir adsorption isotherm equation can be derived theoretically by assuming an equilibrium between the molecules of the adsorbed substance on the surface of the adsorbent with the unsorbed molecules of the substance. The Langmuir equation assumes that the adsorption occurs on a specified surface of homogeneous adsorbents $[14,15]$. In addition, on the adsorption of the Langmuir isotherms only form a single layer at maximum adsorption, each atom is adsorbed only at a specific location on the surface of the adsorbent, and each part of the surface can hold only one molecule or atom. The Langmuir adsorption isotherm equation can be written as follows:

$$
q_{e}=\frac{q_{m} \times K_{L} \times C_{e}}{1+K_{L} \times C_{e}}
$$

where $\mathrm{q}(\mathrm{mg} / \mathrm{kg})$ is the amount of adsorbate per unit of adsorbent mass, $\mathrm{C}_{\mathrm{e}}(\mathrm{mg} / \mathrm{kg})$ is the concentration of adsorbate at equilibrium, $\mathrm{q}_{\mathrm{m}}(\mathrm{mg} /$ $\mathrm{kg}$ ), and $\mathrm{K}_{\mathrm{L}}(\mathrm{mg} / \mathrm{kg})$ are Langmuir constants associated with adsorption capacity and adsorption rate.

The parameters in the adsorption of Langmuir isotherms can be determined by converting the Langmuir equation into the following linear equation:

$$
\frac{C_{e}}{q_{e}}=\frac{C_{e}}{q_{m}}+\frac{1}{q_{m} \times K_{L}}
$$

where the 1 / qm value can be determined from the slope of the $\mathrm{C}_{\mathrm{e}} / \mathrm{q}_{\mathrm{e}}$ plot curve with $\mathrm{C}_{\mathrm{e}}$.

\section{Freundlich Adsorption Isotherm}

For a small concentration range and a liquid mixture, isoterm adsorption can be illustrated by the empirical equations set forth by Freundlich. Freundlich Adsorption Isotherm is based on the assumption that the adsorbent has a heterogeneous surface and that each molecule has different potential of adsorption. This equation is the most widely used equation today.

The Freundlich equation also shows a reversible or irreversible adsoption process, and it is not forbidden to form a monolayer adsorption process [16].

The Freundlich isotherm adsorption equation is as follows [17]:

$$
Q_{e}=K_{f} \times C_{e}^{\frac{1}{n}}
$$

then the equation is reorganized by converting it into a logarithmic equation to obtain the following linear equation: 


$$
\log Q_{e}=\log _{f}+\frac{1}{n} C_{e}
$$

where the value of $K_{f}$ is Freundlich isoterm constant (mg / g), $Q_{e}=$ number of adsorbed $\mathrm{mg}$ in each gram of adsorbent or adsorption capacity, $\mathrm{C}_{\mathrm{e}}=$ concentration after adsorption and $\mathrm{n}=$ adsorption intensity [18]. The $\mathrm{n}$ values range from zero to one reflecting the intensity of adsorption or surface heterogeneity.

\section{Temkin Adsorption Isotherm}

This type of isotherm contains factors explicitly related to the adsorbate-adsorbate interactions. Regardless of the very low or high concentration values, this model assumes that the energy or heat of adsorption (temperature function) of all molecules in the layer will decrease linearly with increasing coverage [19] and [20], due to the adsorbate-adsorbat interaction [21], due to the adsorbatic displacement and adsorbate adsorption uniformly distributed between layers [22].

As implicit in the equation, the derivative of this model can be characterized by the uniform distribution of union energy (up to some maximum binding energy) which can be done by plotting the quantities absorbed by $\mathrm{q}_{\mathrm{e}}$ versus $\operatorname{lnC}_{\mathrm{e}}$ and constants whose value can be determined from the slope and intercept.

Here is the Temkin isothermal adsorption equation:

$$
q_{e}=\frac{R T}{b_{T}} \ln C_{e}
$$

And the linear form of the equation with the bond energy can be written as follows:

$$
q_{e}=B_{T} \ln A_{T}+B_{T} \ln C_{e}
$$

where $\mathrm{B}_{\mathrm{T}}=(\mathrm{RT}) / \mathrm{b}_{\mathrm{T}}$, where $\mathrm{T}$ represents the absolute temperature, $\mathrm{R}$ is the gas contant $(8.314 \mathrm{~J} / \mathrm{mol} \mathrm{K})$. $\mathrm{b}_{\mathrm{T}}$ is a constant associated with the heat of the adsorbs. $\mathrm{A}_{\mathrm{T}}$ is a bond constant in a state of equilibrium ( $\mathrm{L} /$ min) which depends on the maximum binding energy of the adsorbate and the adsorbent.

\section{Dubinin Radushkevich (D-R) Adsorption Isotherm}

Dubinin-Radushkevich isotherms are generally applied to describe the adsorption mechanism with the distribution of Gaussian energy on heterogeneous surfaces [23] Dubinin-Radushkevich (D-R) The isothermal model predicts that the adsorption process follows a pore filling mechanism and is expressed by a semi-empirical equation. The assumption of this model is that the adsorption has a multilayer character, involving van der Waals forces and is applicable to the physical adsorption process [21].

$\mathrm{D}-\mathrm{R}$ isotherms investigate the nature of the adsorption process. D$\mathrm{R}$ isotherms do not consider the surface of an adsorbent to be homogeneous or have a constant absorption potential. The isothermal DR can be applied to estimate the average free energies of adsorption (E), where if the value of $E$ is between 1 and $16 \mathrm{~kJ} / \mathrm{mol}$, then the physical adsorption is applied, and if the value is more than $16 \mathrm{~kJ} / \mathrm{mol}$, then Chemisorption applied [24].

The D-R isotherm adsorption model is presented linearly with the equation as given below:

$$
\ln q_{e}=\ln q_{s}-K_{a d} \times \varepsilon^{2}
$$

where $\mathrm{q}_{\mathrm{e}}, \mathrm{q}_{\mathrm{s}}, \mathrm{K}_{\mathrm{ad}}$, is the amount of adsorbate on the adsorbent at the time of equilibrium $(\mathrm{mg} / \mathrm{g}) ; \mathrm{q}_{\mathrm{s}}=$ theoretical isothermal saturated capacity $(\mathrm{mg} / \mathrm{g}) ; \mathrm{K}_{\mathrm{ad}}=$ isothermal adsorption constant Dubinin-Radushkevich $\left(\mathrm{mol}^{2} / \mathrm{kJ}^{2}\right)$ and $\varepsilon=$ Dubinin-Radushkevich isothermal constants. Where $\varepsilon$ can be determined using the following equation:

$$
\varepsilon=R T \ln \left(1+\frac{1}{C_{e}}\right)
$$

where $\mathrm{T}$ is the absolute temperature. The value of $\mathrm{q}_{\mathrm{m}}$ and $\mathrm{K}_{\mathrm{ad}}$ can be determined through the intercept and slope of the graph plot lnqe versus $\varepsilon^{2}$. The energy value to be used to determine the adsorption properties which is the average free energy of adsorbate molecule $(\mathrm{kJ} / \mathrm{mol})$ [22], E can be calculated using the following equation:

$$
E=\frac{1}{\sqrt{2 K_{a d}}}
$$

\section{Kinetics adsorption}

The study of adsorption kinetics describes the absorption rate of solutes that determines the residence time of adsorbate adsorption at the solid-solution interface including the diffusion process. The adsorption mechanism depends on the physical and chemical properties of the adsorbent as well as on the mass trasnfer process [25]. The adsorption kinetics model can be analyzed using a pseudo-first-order reaction kinetics equation [26], the second pseudo-order [15] and Inteerparticle diffusion as follows:

\section{The first-order pseudo-kinetic equation of Lagergen}

The first-order pseudo-kinetic equation of Lagergen describes the adsorption process in a solid-liquid system based on the capacity of solids $[27,28,29]$. The general equation of the first-order pseudoreaction kinetics is the following:

$$
\frac{d q}{d t}=K_{a d}\left(q_{e q}-q_{t}\right)
$$

where, qeq: The number of phosphate ions adsorbed per unit weight of the adsorbent on balance $(\mathrm{mg} / \mathrm{g})$, $\mathrm{q}_{\mathrm{t}}$ : The amount of cholesterol adsorbent per unit weight of adsorbent at time $\mathrm{t}(\mathrm{mg} / \mathrm{g}), \mathrm{K}_{\mathrm{ad}}$ : The pseudo-order first order adsorption constant $(1 / \mathrm{min})$ After integration with the limit, for $\mathrm{t}=0, \mathrm{q}=0$ the equation becomes:

$$
\log \left(q_{e q}-q\right)=\log q_{e q}-\frac{K_{a d} t}{2.303}
$$

The first-pseudo-order equation can be correlated with the following equation:

$$
k_{1}=A_{1}\left[C_{0}\right]^{\beta_{1}}
$$

where $\mathrm{C}_{0}$ is the initial phosphate concentration of the liquid-solid phase (mmol/L) $A_{1}$ and $\beta_{1}$ are first-order pseudo-reaction constants [29].

\section{The second-order pseudo-kinetic equation of Lagergen}

The second-order pseudo-kinetics equation shows how the adsorption rate of an adsorbate depends on the absorption capacity of the adsorbent rather than on the adsorbate concentration [15].

The second-pseudo-order equation has the following advantages: it allows evaluation of the effective adsorption capacity, the initial absorption rate and the rate constant of the second pseudo-second kinetic model without knowing any parameters first.

The adsorption rate on the surface of the adsorbent should be proportional to the thrust force multiplied by an area. The rate of the second pseudo-order reaction can depend on the amount of solute being absorbed on the surface of the adsorbent and the amount of adsorbate absorbed at equilibrium. (Ho, et al., 2006). The pseudo-second order adsorption kinetics equation can be written as follows:

$$
\frac{d q}{d t}=k\left(q_{e q}-q\right)^{2}
$$

where $\mathrm{k}$ is the pseudo second order adsorption speed constant ( $\mathrm{g} / \mathrm{mg}$.min). Integration of the above equation with boundary condition $\mathrm{t}=0, \mathrm{q}=0$ obtained the following equation:

$$
\frac{t}{q_{t}}=\frac{1}{k q_{e q}^{2}}+\frac{t}{q_{e q}}
$$


The intercept of the pseudo-order velocity realization linearization is a two-order velocity constant, $\mathrm{k}$. The compatibility between the experimental data and the model prediction value is expressed by the correlation coefficient $\left(\mathrm{R}^{2}\right)$, where the value of the large correlation coefficient indicates the suitability of the experimental data on the adsorption kinetics model.

\section{Intraparticle diffusion Mechanism}

The adsorption mechanism can be explained by using an intraparticle diffusion model. The adsorption process consists of several stages such as movement of particles from outside the adsorbent to the surface of the adsorbent and then followed by molecular diffusion into the pores. Intra-particle diffusion is generally a slow process and is considered a rate-determining stage in the adsorption process. During the adsorption process using the batch transfer method of adsorbate particles to the pores of adsorbent is the rate determining stage. Intraparticle adsorption is expressed by Weber and Morris equationsm [15].

The diffraction model of Weber and Morris intraparticles is represented as follows:

$$
q_{t}=K_{i d} t^{\frac{1}{2}}
$$

where $\mathrm{K}_{\text {id }}$ is an intra-particle diffusion rate constant ( $\mathrm{mg} / \mathrm{g}$ min $1 / 2$ ). Referring to this model, the plot of the teradsorb versus square root of the contact time will result in a curve of a straight line passing the origin $(0,0)$ (Weber and Morris, 1963). When the resulting plot does not pass through the origin, it indicates the degree of control of film diffusion and intraparticle diffusion is not the only determinant of rate [22].

Linear curves with larger radii illustrate the faster adsorption process This process occurs at the beginning of the adsorption process and possibly describes the adsorption process controlled by the movement of molecules onto the surface of the adsorbent solid. The smaller radient curves represent a slower process. This stage occurs after the first stage and is probably an adsorption process controlled by intra-particle diffusion.

\section{Adsorption Thermodynamics}

The adsorption process of adsorbate is often studied by calculating several thermodynamic parameters of the adsorption process ie $\Delta \mathrm{G}^{\circ}$, $\Delta \mathrm{H}^{\circ}$ and $\left.\Delta \mathrm{S}^{\circ}\right)$. Gibbs free energy calculation $\left(\Delta \mathrm{G}^{\circ}\right)$ of the adsorption process can be done by equation [32]:

$$
\Delta G^{\circ}=-R T \ln K_{d}
$$

where $\mathrm{R}, \mathrm{T}$, and $\mathrm{Kd}$ are gas constants, temperature and distribution coefficients. The Kd can be calculated using the following equation [33]:

$$
K_{d}=\frac{C_{A e}}{C_{e}}
$$

where $\mathrm{C}_{\mathrm{Ae}}$ is the amount of adsorbate per unit of adsorbent mass, whereas $\mathrm{C}_{e}$ is the concentration of adsorbate in solution. enthalpy $\left(\Delta \mathrm{H}^{\circ}\right)$ and entropy $\left(\Delta \mathrm{S}^{\circ}\right)$ of the adsorption process can be calculated using the slope and intercept of Van't equations below [34]:

$$
\ln K_{d}=-\frac{\Delta H^{\circ}}{R T}+\frac{\Delta S^{\circ}}{R}
$$

The negative value of gibss energy shows a spontaneous adsorption process. A higher negative value indicates that the process is energetically preferred over other mechanisms. While the negative value of the enthalpy confirmed the exothermic adsorption properties. The negative of entropy indicates the low degree of freedom of the adsorbate particles in the liquid-solid interface during the adsorption process [22].

\section{Surface characteristic of the adsorbent}

Surface area and porous size distribution of ZSM-5 sample were measured by nitrogen adsorption analysis (Quantachrome V5.02). Crystal structure of sample was determined by performing X-ray diffraction $(\mathrm{XRD})$ on with a Philips X'Pert Powder $\mathrm{Cu} \mathrm{K} \alpha$ radiation source $(\lambda=1.54 \AA)$ in the $2 \theta$ between $5-40^{\circ} \mathrm{X}$-ray diffraction spectrometer. Surface morphologies were examined by a scanning electron microscope (SEM, JEOL (JSM 6390) with the working distance of $9.9 \mathrm{~mm}$ and an accelerating voltage of $30 \mathrm{keV}$. Infrared (IR) absorption spectroscopy spectra were measured at room temperature on a Fourier transform infrared (FTIR) spectroscopy (8400s SHIMADZU spectrometer) using the $\mathrm{KBr}$ pellet technique. The spectra were measured in $4000-400 \mathrm{~cm}^{-1}$.

\section{RESULTS AND DISCUSSION}

\section{Synthesis of ZSM-5 From Kaolin}

This study has been successfully synthesized ZSM-5 directly from Bangka Kaolin without organic templates using silicalite seed. Synthesis method adapted from research Prasetyoko et al. [11] and Hartanto, [12] with a molar composition ratio $10 \mathrm{Na}_{2} \mathrm{O}: 100 \mathrm{SiO}_{2}$ : $2 \mathrm{Al}_{2} \mathrm{O}_{3}: 1800 \mathrm{H}_{2} \mathrm{O}$ and silicalite seed as much as $1 \%$ of the mass of solids. Precursors include kaolin used as a source of alumina and silica;

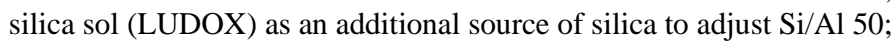
$\mathrm{NaOH}$ as $\mathrm{Na}^{+}$ion source and agent of mineralization; silicalite seed crystals to trigger growth and aquademin as a source of $\mathrm{H}_{2} \mathrm{O}$. Stages of the synthesis include hydrolysis, gelation, curing and crystallization.

\section{XRD-Characterization}

ZSM-5 synthesized were characterized using X-ray diffraction (XRD) with a Philips X'Pert Powder $\mathrm{Cu} \mathrm{K} \alpha$ radiation source $(\lambda=1.54$ $\AA$ ) in the $2 \theta$ between $5-40^{\circ}$. Characterization of X-ray diffraction is used to determine the structure, crystal phase and crystallinity. Crystallinity calculated according to equation 3.1 with specific comparisons using XRD peaks ZSM-5 synthesized [11] as a comparison. X-ray diffractogram of kaolin samples, reference ZSM-5 and ZSM-5 with a crystallization time of 12, 24, 48 and 72 hours are shown in Figure 4.4.

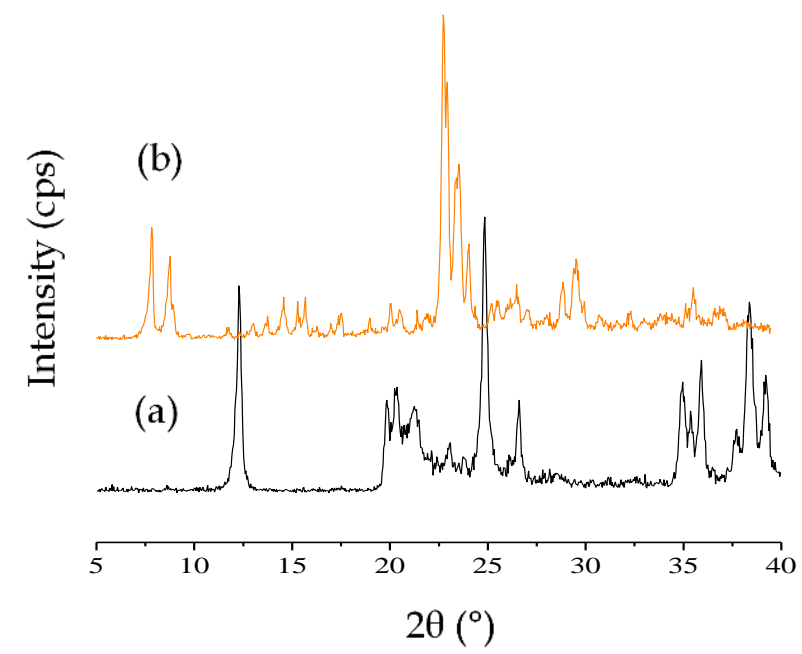

Fig. 2 Difraktogram (a) kaolin and (b). ZSM-5 synthesis from Bangka Kaolin.

Figure 2 shows the XRD samples of kaolin (a) and ZSM-5 result of synthesis with Bangka kaolin (b). Kaolin Bangka diffractogram in Fig. 2 (a) shows the peak at $2 \theta$ about $12,20-27$ and 35-40 ${ }^{\circ}$. Base on Fig 1 Kaolinite is the main content of the kaolin with height content because have height peak [35]. Fig. 2 (b) did not indicate kaolin content and that only have ZSM-5 crystal phase, it show difractogram peaks only ZSM5 synthesized [12] And the height $2 \theta$ pattern showed sharp peaks with high intensity. Therefore, crystallinity of ZSM-5 have height crystallinity.

\section{FTIR-Characterization}

Carracterization with Infrared spectroscopic show in Fig 2. This suggests that the bonds have experienced disconnection kaolin and begin to form new bonds. This data is supported by X-ray diffraction that the kaolin samples has been transformed into ZSM-5. 


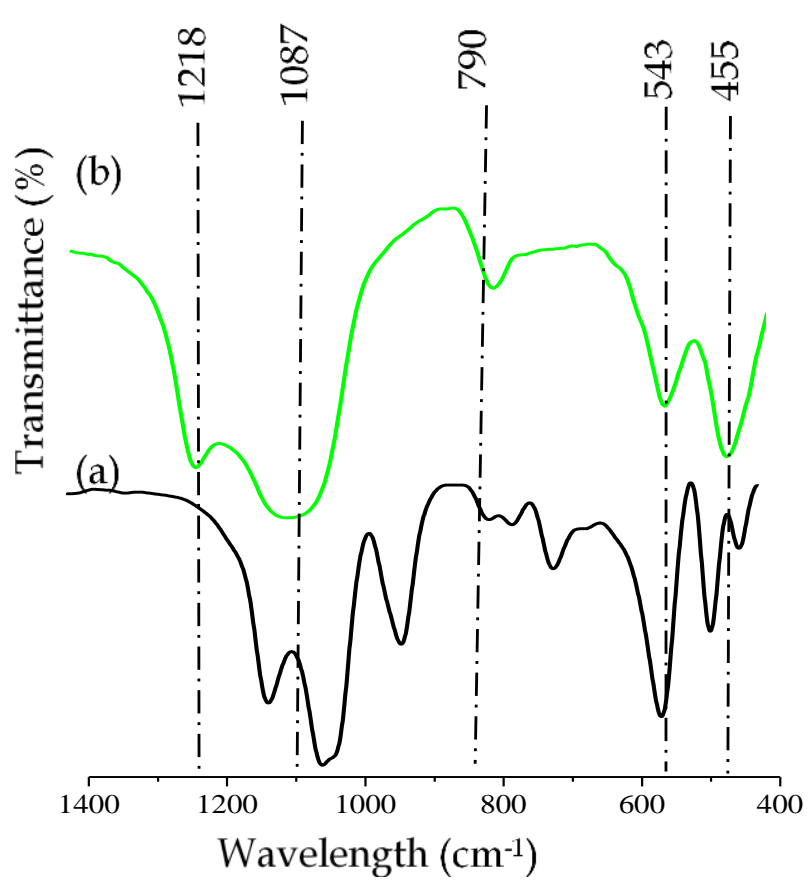

Fig. 3 Infrared spectra of samples (a) kaolin, (b) ZSM-5 Synthesis from kaolin Bangka

The spectra of samples ZSM-5 in Figure 3 shows 5 peaks at wave numbers around $1221 \mathrm{~cm}^{-1}$ and $1102 \mathrm{~cm}^{-1}$ resulting from the asymmetric stretching vibration TOT bond; $796 \mathrm{~cm}^{-1}$ of bond stretching vibration symmetry T-O-T; $546 \mathrm{~cm}^{-1}$ shows the framework vibration Pentasil ring that is characteristic of the structure of the MFI-type zeolite and $450 \mathrm{~cm}^{-1}$ result from vibration buckling TOT, where T is Si or $\mathrm{Al}$ atoms [36]. According to Mohammed, [37] peak at $450 \mathrm{~cm}^{-1}$ and $542 \mathrm{~cm}^{-1}$ is the characterization of crystalline ZSM-5 which has the form of the MFI structure. The same was reported by Somani et al., [38] that the increased peak at wave number $550 \mathrm{~cm}^{-1}$ shows that the concentration of the higher MFI structure. These results are consistent with the XRD diffractogram fourth sample, the sample ZSM-5.

\section{SEM-Characterization}

Another Observations with Scanning Electron Microscopy (SEM) was used to determine the morphology and size of the crystal sample with Energy Dispersive include an X-ray (EDX) to determine the content of the elements contained in the sample. Morphology ZSM-5 samples as seen in Figure 4.

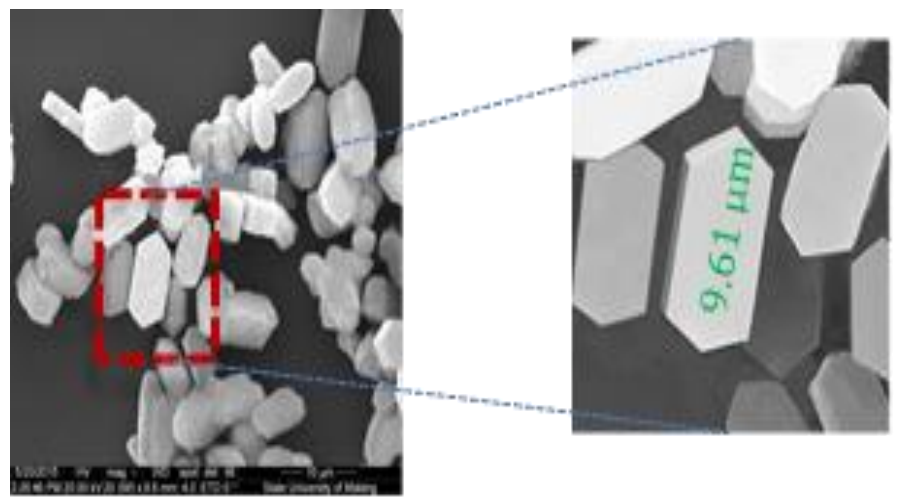

Fig. 4 ZSM-5 morphology was characterized with SEM at 10,000 times magnification of the sample ZSM- 5 from Bangka Kaolin.

The results of SEM samples ZSM-5 with a crystallization are shown the presence of large rectangular crystals with a size of $9.61 \times 3.8 \times 1.3$ $\mu \mathrm{m}$. The morphology of crystal shows ZSM-5 samples are seen to have a uniform crystalline form. However, in some parts there were also a large crystal with a size of about $9.61 \times 3.30 \times 1,5 \mu \mathrm{m}$ (marked hexagons).

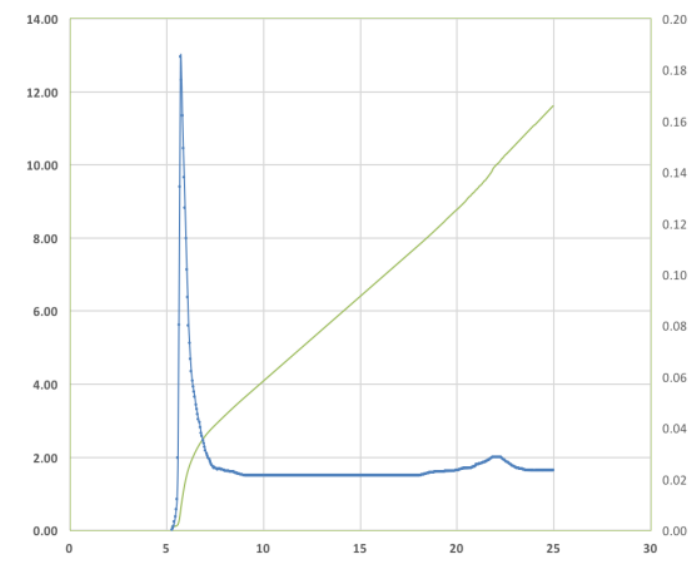

Fig 5. Pore and surface area ZSM-5 synthesis from Bangka kaolin.

The surface area of ZSM-5 calculation uses the BET (Brunauer, Emmet and Teller) calculation model with the assumption that the gas forms an infinite number of layers above a surface [39]. Based on calculations using the BET model, the surface area of the catalyst sample is obtained. The result of isothermal adsorption of nitrogen gas at temperature $77 \mathrm{~K}$ for determination of surface area of one zeolite with ZSM- $5 \mathrm{Si} / \mathrm{Al} 50$ shown that surface area a $333 \mathrm{~m} 2 / \mathrm{g}$ and a pore diameter of 5.72 A and 20-23 A fig 5.

\section{Batch adsorption studies}

\section{Effect of Initial dye concentration}

In order to determine the optimum initial concentration of the target dye, its value was varied (for both dye under study) in the range 50-250 $\mathrm{mg} / \mathrm{L}$, while keeping the temperature, adsorbent mass and the contact time constant at $303 \mathrm{~K}, 0.010 \mathrm{~g}$ and $180 \mathrm{~min}$ respectively. The effect of initial concentration on the removal of CR (congo red) by the adsorbent is indicated in Table 1. It is evident from the table that percentage of CR removal decreases with increase in dye concentrations; however actual amount of the dye adsorbed is increased. This is due to increase in dyes concentration, surface area and active sites of the adsorbent were saturated and hence percentage removal decreases.

\section{Effect of contact time}

In order to determine the optimum contact time, its value was varied in the range of 20-180 $\mathrm{min}$ in a series of experiments in which the initial target dye concentration, the temperature and adsorbent amount were kept constant at $100 \mathrm{mg} / \mathrm{L}, 303 \mathrm{~K}$ and $0.010 \mathrm{~g}$ respectively. The effect of contact time on the removal of CR by the adsorbent is indicated in Table 2. It is indicated that uptake of the dye is rapid in the beginning and then it becomes constant. The adsorption curves are single, smooth, and continuous leading to saturation and indicate the possible monolayer coverage on the surface of adsorbents by the molecules.

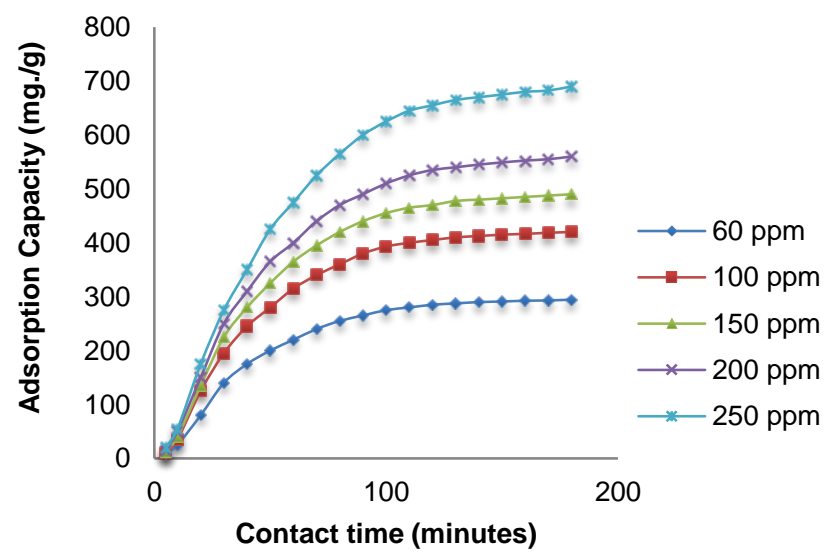

Fig 5. Effect of initial concentration and contact time. 


\section{Effect of Temperature}

In order to determine the optimum initial concentration of the target dye, its value was varied in the range $50-250 \mathrm{mg} / \mathrm{L}$, while keeping the initial concentration, adsorbent mass and the contact time constant at $250 \mathrm{mg} / \mathrm{L}, 0.010 \mathrm{~g}$ and $180 \mathrm{~min}$ respectively.

The graphic Temperature VS Adsorption eff as shown in Table 3 indicated that uptake of the dye is rapid in the low temperature and becomes decreasing in high temperature. It demonstrates that the increasing temperature, increasing kinetics energy of adsorbate and reduces the ability of interactions between adsorbent-adsorbate.

\section{Adsorption isotherms}

Table $4 \mathrm{a}$ tabulates the parameters of the isotherm models employed in this study at $30^{\circ} \mathrm{C}$. These models are: Langmuir, Freundlich, Temkin, and Dubinin-Radushkevich. The suitability of the model was
The Temkin isotherm model has been developed on the concept of chemisorptions. It assumes that the heat of adsorption of the molecules of the adsorbate linearly decreases with adsorbent layer coverage due to adsorbate-adsorbent interactions. The equilibrium binding constant, $\mathrm{bT}(\mathrm{mol} / \mathrm{g})$ was determined from the Temkin isotherm model.

The Dubinin-Radushkevich isotherm model can be used to examine the porosity apparent free energy, E and the characteristics of the adsorption process. The values of $\mathrm{E}$ for ZSM-5 at 30, 40, and $50^{\circ} \mathrm{C}$ are $11.952,129.099$ and $\mathrm{kJ} / \mathrm{mol}$, respectively. Since all these values range between 1 and $8 \mathrm{~kJ} / \mathrm{mol}$, it shows that physisorption was responsible for the adsorption of CR dye onto ZSM-5, but all of the values are higher than $8 \mathrm{~kJ} / \mathrm{mol}$, it can be proposed that the adsorption was occured chemically [40].

After summarizing all the important parameters for each isotherm, the value of $\mathrm{R}^{2}$ was used to judge the most suitable model for the

Table 5 a. Isotherm Parameters for CR dye adsorption onto ZSM- 5 at $30^{\circ} \mathrm{C}$.

\begin{tabular}{|c|c|c|c|c|c|c|c|c|c|c|c|c|}
\hline \multicolumn{3}{|c|}{ langmuir } & \multicolumn{3}{|c|}{ Freundlich } & \multicolumn{3}{|c|}{ Temkin } & \multicolumn{4}{|c|}{ D-R } \\
\hline $\begin{array}{c}q_{m} \\
(m g / g)\end{array}$ & $\begin{array}{c}\mathrm{K}_{\mathrm{L}} \\
(\mathrm{l} / \mathrm{g})\end{array}$ & $\mathrm{R}^{2}$ & $\mathrm{~K}_{\mathrm{f}}$ & $\mathrm{n}$ & $\mathrm{R}^{2}$ & $\mathrm{~K}_{\mathrm{T}}$ & $\begin{array}{c}\mathrm{B}_{\mathrm{T}} \\
(\mathrm{mol} / \mathrm{KJ})\end{array}$ & $\mathrm{R}^{2}$ & $q_{m}(m g / g)$ & B $\left(10^{-5}\right)$ & $\begin{array}{c}E \\
(\mathrm{KJ} / \mathrm{mol})\end{array}$ & $\mathrm{R}^{2}$ \\
\hline 97,08 & 0,009 & 0,993 & $13,6 \times 10^{4}$ & 0,48 & 0,949 & 0,0036 & $-788,91$ & 0,933 & 137,15 & 350 & 11,952 & 0,855 \\
\hline
\end{tabular}

Table 5 b. Isotherm Parameters for CR dye adsorption onto ZSM- 5 at $40^{\circ} \mathrm{C}$.

\begin{tabular}{|c|c|c|c|c|c|c|c|c|c|c|c|c|}
\hline \multicolumn{3}{|c|}{ langmuir } & \multicolumn{3}{|c|}{ Freundlich } & \multicolumn{3}{|c|}{ Temkin } & \multicolumn{4}{|c|}{ D-R } \\
\hline $\begin{array}{c}q_{m} \\
(m g / g)\end{array}$ & $\begin{array}{c}K_{L} \\
(1 / g)\end{array}$ & $\mathrm{R}^{2}$ & $\mathrm{~K}_{\mathrm{f}}$ & $\mathrm{n}$ & $\mathrm{R}^{2}$ & $\mathrm{~K}_{\mathrm{T}}$ & $\begin{array}{c}\mathrm{B}_{\mathrm{T}} \\
(\mathrm{mol} / \mathrm{KJ})\end{array}$ & $\mathrm{R}^{2}$ & $\mathrm{q}_{\mathrm{m}}(\mathrm{mg} / \mathrm{g})$ & B $\left(10^{-5}\right)$ & $\begin{array}{c}\mathrm{E} \\
(\mathrm{KJ} / \mathrm{mol})\end{array}$ & $\mathrm{R}^{2}$ \\
\hline 40,98 & 0,083 & 0,965 & 3180,5 & 0,99 & 0,889 & 7,48 & $\begin{array}{l}-127,09 \\
\end{array}$ & 0,929 & 80,97 & 3 & 129,099 & 0,630 \\
\hline
\end{tabular}

Table 5 c. Isotherm Parameters for CR dye adsorption onto ZSM- 5 at $50^{\circ} \mathrm{C}$

\begin{tabular}{|c|c|c|c|c|c|c|c|c|c|c|c|c|}
\hline \multicolumn{3}{|c|}{ langmuir } & \multicolumn{3}{|c|}{ Freundlich } & \multicolumn{3}{|c|}{ Temkin } & \multicolumn{4}{|c|}{$\mathrm{D}-\mathrm{R}$} \\
\hline $\begin{array}{c}q_{m} \\
(m g / g)\end{array}$ & $\begin{array}{c}\mathrm{K}_{\mathrm{L}} \\
(\mathrm{l} / \mathrm{g})\end{array}$ & $\mathrm{R}^{2}$ & $\mathrm{~K}_{\mathrm{f}}$ & $\mathrm{n}$ & $\mathrm{R}^{2}$ & $\mathrm{~K}_{\mathrm{T}}$ & $\begin{array}{c}\mathrm{B}_{\mathrm{T}} \\
(\mathrm{mol} / \mathrm{KJ})\end{array}$ & $\mathrm{R}^{2}$ & $q_{m}(m g / g)$ & B $\left(10^{-5}\right)$ & $\begin{array}{c}E \\
(\mathrm{KJ} / \mathrm{mol})\end{array}$ & $\mathrm{R}^{2}$ \\
\hline 49,02 & 0,019 & 0,995 & $18,2 \times 10^{8}$ & 0,33 & 0,944 & 0,0062 & $\begin{array}{l}-870,54 \\
\end{array}$ & 0,917 & 60,57 & 570 & 9,3659 & 0,870 \\
\hline
\end{tabular}

determined by choosing the model with the value of $\mathrm{R}^{2}$ closest to 1 . adsorption of CR dye onto ZSM-5. The results obtained were: DubininAccording to theoretical Langmuir adsorption isotherm, The Langmuir $\quad$ Radushkevich $\left(R^{2}=0,855\right)<$ Temkin $\left(R^{2}=0,933<\right.$ Freudlich $\left(R^{2}=\right.$

\begin{tabular}{|c|c|c|c|c|c|c|c|c|c|c|}
\hline \multirow{2}{*}{$\begin{array}{l}\text { Parameters } \\
\text { Concentration } \\
\text { (ppm) }\end{array}$} & \multicolumn{5}{|c|}{ Adsorption Efficiency (\%) } & \multicolumn{5}{|c|}{ Amount of adsorbed $q(\mathrm{mg} / \mathrm{g})$} \\
\hline & 50 & 100 & 150 & 200 & 250 & 50 & 100 & 150 & 200 & 250 \\
\hline CR & $98,2 \%$ & $84,0 \%$ & $65,3 \%$ & $56,0 \%$ & $55,2 \%$ & 294,5 & 420,0 & 490 & 560 & 690 \\
\hline Parameters & & Adsc & on Effic & $\mathrm{y}(\%)$ & & & Amoun & dsork & $(\mathrm{mg} / \mathrm{g})$ & \\
\hline $\begin{array}{l}\text { Contact time } \\
\text { (min) }\end{array}$ & 20 & 60 & 100 & 140 & 180 & 20 & 60 & 100 & 140 & 180 \\
\hline CR & $25,0 \%$ & $63,0 \%$ & $78,6 \%$ & $82,5 \%$ & $84,0 \%$ & 125 & 315 & 393 & 412,5 & 420,0 \\
\hline
\end{tabular}

Tabel 4. Effect of Temperature on Adsorption efficiency and capacity.

\begin{tabular}{ccccccc}
\multicolumn{2}{c}{ Tabel 4. Effect of Temperature on Adsorption efficiency and capacity. } \\
\hline Parameters & \multicolumn{2}{c}{ Adsorption Efficiency (\%) } & \multicolumn{3}{c}{ Amount of adsorbed $\mathbf{q} \mathbf{~ ( m g / g )}$} \\
\hline Temperature (K) & 303 & 313 & 323 & 303 & 313 & 323 \\
\hline CR & 55,2 & 52,4 & 47,2 & 690 & 655 & 590 \\
\hline
\end{tabular}

equation assumes that the adsorption occurs on a specified surface of homogeneous adsorbents [14][15]. In addition, on the adsorption of the Langmuir isotherms only form a single layer at maximum adsorption, each atom is adsorbed only at a specific location on the surface of the adsorbent, and each part of the surface can hold only one molecule or atom. This isotherm adsorption can be used to determine the highest adsorption capacity that corresponds to the complete monolayer coverage on ZSM-5 [40]. The values of $\mathrm{q}_{\mathrm{m}}$ at different temperatures are shown in Tables $4 \mathrm{a}-4 \mathrm{c}$. Maximum qm was $97,08 \mathrm{mg} / \mathrm{g}$ at $30^{\circ} \mathrm{C}$.

The Freundlich isotherm is used to illustrate the non-ideal heterogeneous behavior of the adsorption process. The extent of adsorption can be reflected by the value of $K_{F}$. It was found that the extent of adsorption at $50^{\circ} \mathrm{C}\left(\mathrm{K}_{\mathrm{F}}=18,2 \times 10^{8}\right)$ was much higher than that of $30^{\circ} \mathrm{C}\left(\mathrm{K}_{\mathrm{F}}=13,6 \times 10^{4}\right)$. The value of $\mathrm{n}$ calculated from the Freundlich model was close to 1 , it is reflecting the high intensity of adsorption or surface heterogeneity [41].
0,949) <Langmuir $\left(\mathrm{R}^{2}=0,993\right)$ which suggests that the adsorption process can best be described using Langmuir model.

\section{Kinetic studies}

In order to investigate the adsorption kinetics of CR dye, three different kinetic models, namely pseudo-first-order, pseudo-secondorder and intraparticle diffusion models were used in this study. The pseudo-first-order kinetic model was used to predict the adsorption kinetics. Plots of $\ln \left(\mathrm{q}_{\mathrm{e}}-\mathrm{q}_{\mathrm{t}}\right)$ versus $\mathrm{t}$ gave a straight line, with negative slope of $k_{1}$ and intercept of lnqe. Inferring from the values of $\mathrm{R}^{2}$ obtained from the adsorption of CR dye onto ZSM-5, $\mathrm{R}^{2}$ values are higher than those obtained for the pseudo-second-order model.

On the other hand, the plots of t/qt versus $t$ for the pseudo-secondorder model were also used to study the adsorption process. As can be seen from Table 5 , the values of $\mathrm{R}^{2}$ calculated for the adsorption process are lower than that obtained for the pseudo-first order model. This 
Tabel 6. Parameters of the Pseudo-first-order, Pseudo-second-order and Internal Diffusion models for ZSM-5 at $30^{\circ} \mathrm{C}$.

\begin{tabular}{|c|c|c|c|c|c|c|}
\hline & & $\begin{array}{l}\text { Initial Dye } \\
\text { Conc }\end{array}$ & $\begin{array}{l}\text { Initial Dye } \\
\text { Conc }\end{array}$ & $\begin{array}{c}\text { Initial Dye } \\
\text { Conc }\end{array}$ & $\begin{array}{l}\text { Initial Dye } \\
\text { Conc }\end{array}$ & $\begin{array}{l}\text { Initial Dye } \\
\text { Conc }\end{array}$ \\
\hline Kinetics Model & Parameter & $60(\mathrm{mg} / \mathrm{L})$ & $100(\mathrm{mg} / \mathrm{L})$ & $150(\mathrm{mg} / \mathrm{L})$ & 200 (mg/L) & 250 (mg/L) \\
\hline \multirow[t]{4}{*}{ Pseudo First Order } & $\mathrm{K}_{1}\left(\min ^{-1}\right)$ & 0,0323 & 0,0309 & 0,03 & 0,0277 & 0,0274 \\
\hline & $\mathrm{Q}_{\mathrm{e}}$ (experimental) & 294,5 & 420 & 490 & 560 & 670 \\
\hline & $\mathrm{Q}_{\mathrm{e}}$ (calculated) & 457,14 & 594,55 & 689,45 & 769,16 & 977,01 \\
\hline & $\mathrm{R}^{2}$ & 0,9949 & 0,9969 & 0,9980 & 0,9969 & 0,9952 \\
\hline \multirow[t]{4}{*}{ Pseudo Second Order } & $\mathrm{K}_{2}\left(\min ^{-1}\right)$ & 0,3825 & 0,1503 & 0,1846 & 0,1547 & $7,2 \times 10^{-6}$ \\
\hline & $\mathrm{Q}_{\mathrm{e}}$ (experimental) & 294,5 & 420 & 490 & 560 & 670 \\
\hline & $\mathrm{Q}_{\mathrm{e}}$ (calculated) & 5,4230 & 8,6505 & 7,8064 & 8,5251 & 1250 \\
\hline & $\mathrm{R}^{2}$ & 0,9284 & 0,9365 & 0,9444 & 0,9503 & 0,9364 \\
\hline \multirow[t]{3}{*}{ Internal Diffusion } & $\mathrm{K}_{\text {id }}\left(\mathrm{g} / \mathrm{mg} / \mathrm{min}^{1 / 2}\right)$ & 29,187 & 40,052 & 47,933 & 54,904 & 69,085 \\
\hline & $\mathrm{C}(\mathrm{mg} / \mathrm{g})$ & $-32,207$ & $-29,570$ & $-49,279$ & $-66,121$ & $-101,84$ \\
\hline & $\mathrm{R}^{2}$ & 0,9349 & 0,9365 & 0,9351 & 0,9503 & 0,959 \\
\hline
\end{tabular}

Tabel 7. Thermodynamic parameters for adsorption of CR dye onto ZSM-5

\begin{tabular}{ccccc}
\hline & & \multicolumn{3}{c}{$\Delta \mathrm{G}^{\circ}(\mathrm{kJ} / \mathrm{mol})$} \\
\cline { 3 - 4 } $\mathrm{H}^{\circ}(\mathrm{kJ} / \mathrm{mol})$ & $\Delta \mathrm{S}^{\circ}(\mathrm{kJ} / \mathrm{mol})$ & $303 \mathrm{~K}$ & $313 \mathrm{~K}$ & $323 \mathrm{~K}$ \\
\hline$-188,201$ & 0,594 & $-8,2338$ & $-2,2943$ & $-3,6452$ \\
\hline
\end{tabular}

shows that adsorption of CR dye onto ZSM-5 more fit to the pseudofirst order model.

Adsorption rate is controlled by several factors which include: diffusion of the solute from the solution to the film surrounding the particle, diffusion from the medium to the particle surface, diffusion from the surface to the internal sites (surface diffusion or pore diffusion) and uptake which can involve several mechanisms such as physicochemical adsorption, ion- exchange, precipitation or complexation.[42,43,44] The most important mechanism controlling adsorption kinetics is the diffusion mechanisms such as the initial curved portion which occurred due to rapid external diffusion and surface adsorption [45].

when a linear plot using the linear equations of intraparticle diffusion gives the value of $\mathrm{C}=0$, it can be concluded that intraparticle diffusion is the only rate determining step. When the plot does not produce a curve passing through the origin $(0,0)$ or intercept $(\mathrm{C}=0)$, it indicates that in the adsorption process, the degree of control of film diffusion and intraparticle diffusion is not the only rate determiner. In this study, the plots obtained were non-linear. Even the $\mathrm{R}^{2}$ value closes to 1 . The non linier plot means that The first phase is the bulk diffusion region, the second is the external mass transfer resistance and the third is the intra-particle mass transfer resistance [13].

Comparing the values of $\mathrm{R}^{2}$ for the kinetic equations used, adsorption of CR dye onto ZSM-5 can be described by the following kinetic order: pseudo-second-order > intraparticle difussion > pseudofirst-order. It can be concluded that adsorption of CR dye onto ZSM-5 is physically occured. It is because, in the pseudo-first-order-reaction the rate of reaction was driven by one variable it is correlated with our result that the adsorption capacity depends on the concentration of adsorbate. The higher concentration of adsorbate increasing the adsorption kinetics.

\section{Adsorption thermodynamics}

Thermodynamic parameters are important in adsorption studies; they provide a better understanding of the effect of temperature on the adsorption process. The thermodynamic parameters are tabulated in Table 6. The negative values of $\Delta \mathrm{H}^{\circ}$ obtained in the adsorption of $\mathrm{CR}$ dye onto ZSM-5 signify that the adsorption process was exothermic in nature (Table 6). It can be proven from the results of research conducted showed Congo Red adsorption process using ZSM-5 decreased with increasing temperature adsorption.

The $\Delta \mathrm{H}^{\circ}$ value was calculated to be $-188,201 \mathrm{~kJ} / \mathrm{mol}$. In the other hand, the positive values of $\Delta \mathrm{S}^{\circ}$ indicate that increase in randomness occurred at solid-solution interface during the adsorption process. This indirectly shows the affinity of adsorbent toward dye molecules [46]. As contained in Table $6, \Delta \mathrm{G}^{\circ}$ values were negative at all temperatures studied, inferring that the adsorption was spontaneous in nature. While a higher negative value indicates that the process is energetically preferred over other adsorption mechanisms. Since the values of $\Delta \mathrm{G}^{\circ}$ decreased with increasing temperature, it suggests that at higher temperature, the driving force was less, resulting in lower adsorption uptake [47].

\section{CONCLUSION}

In this study, the potential of ZSM-5 for the adsorption of CR dye was investigated. Some of the important findings include:

i. ZSM-5 which are regarded as adsorbents has meso pores which enhance its adsorption activity.

ii. The percentage of CR dye removal by ZSM-5 was inversely proportional to both its initial dye concentration and adsorption temperature.

iii. The best fitted adsorption isotherm for CR dye removal by ZSM-5 was langmuir Isotherm adsorption. This suggests that the adsorption process occurred physically monolayered. The adsorption occurs on a specified surface of homogeneous adsorbents

iv. The best fitted kinetic model for the adsorption process was the pseudo-first-order kinetic model having the highest $\mathrm{R}^{2}$ than another kinetics model.

v. Intra-particle diffusion mechanism occurred in the adsorption process; however, it was not the only controlling mechanism in the adsorption process.

Thermodynamic studies revealed that the adsorption processes was spontaneous in several temperature and exothermic caused by the negative value of $\Delta G^{\circ}$ and $\Delta H^{\circ}$.

\section{ACKNOWLEDGEMENT}

The corresponding author acknowledges this work was funded by the Ministry of Research, Technology and Higher Education. The authors would like to thank Professor Hadi Nur which support this research and instrumental analysis.

\section{REFERENCES}

[1] Bagane, M., Guiza, S., (2000). "Removal of a dye from textile effluents by adsorption”. Ann. Chim. Sci. Mater. 25, pp.615-626.

[2] Imamura, K., Ikeda, E., Nagayasu, T., Sakiyama, T. and Nakanishi, K. (2002). Adsorption Behavior of Methylene Blue and Its Congeners on a Stainless Steel Surface. J. Colloid Interface Sci. 245, 50.

[3] McKay, G., El-Geundi, M. and Nasser, M.M. (1997) Adsorp. Sci. Technol. 15, 251.

[4] El-Geundi, M. (1997). Adsorbents for industrial pollution control. Adsorp. Sci. Technol. 15, 777. 
[5] McKay, G. (1992). The removal of dye colours from aqueous solutions by adsorption on low-cost materials. J. Chem. Technol. Biotechnol. 32, 759.

[6] Dai, M. (1998). Mechanism of adsorption for dyes on activated carbon. J. Colloid Interface Sci. 198, 6.

[7] Gemeay, A.H., El-Sherbiny, A.S. and Zaki, A. (2002). dsorption and kinetic studies of the intercalation of some organic compounds onto $\mathrm{Na}+$ montmorillonite. J. Colloid Interface Sci. 245, 116.

[8] Parida, S.K. and Mishra, B.K. (1996). Adsorption of Styryl Pyridinium Dyes on Alkali Treated Silica. Indian J. Chem. 37A:618.

[9] Holzheu, S. and Hoffmann, H. (2002). dsorption study of cationic dyes having a trimethylammonium anchor group on hectorite using electrooptic and spectroscopic methods. J. Colloid Interface Sci. 245, 16

[10] Perineau, F., Molinier, J. and Gaset, A. (1983). Adsorption de colorants ioniques sur le dechet lainier de carbonisage. Water Res. 17, 559.

[11] D. Prasetyoko, N. Ayunanda, H. Fansuri, D. Hartanto. (2012). Phase transformation of rice husk ash in the synthesis of ZSM-5 without organic template. J. Math. Fund. Sci., 44 A (3) (2012), pp. 250-262.

[12] Hartanto, D, Saputro, O, Utomo, WP, Rosyidah, A, Sugiarso, D, Ersam, T, Nur, H \& Prasetyoko, D. (2016), Synthesis of ZSM-5 directly from Kaolin without organic template: Part-1: Effect of crystallization time. Chemistry - An Asian Journal, 28, pp. 211-215.

[13] Ojedoku, Adedamola Titi n \& Olugbenga Solomon Bello. (2017). Liquid phase adsorption of Congo red dye on functionalized corn cobs, Journal of Dispersion Science and Technology, 38:9, 1285-1294.

[14] Langmuir, I., (1918). The adsorption of gases on plane surfaces ofglass, mica and platinum. J. Am. Chem. Soc. 40, 1361-1367.

[15] Ho, Y.S., Mckay, G., Wase, D.A.J., Foster, C.F., (2000). Study of thesorption of divalent metalions onto peat. Ads. Sci. Technol. 18(7), 639 650 .

[16] Tarapitakcheevin, P., P. Weerayutsil, and K. Khuanmar. (2013). Adsorption of Acid Dye on Activated Carbon Prepared from Water Hyacinth by Sodium Chloride Activation. GMSARN Int. J., 7: 83 - 90

[17] Freundlich, H.M.F., (1906). Uber die adsorption in losungen. Zeitschrift fur Physikalische Chemie (Leipzig) 57A, 385-470.

[18] Dada, A.O., Olalekan, A.P., Olatunya, A.M., Dada, O., (2012). Langmuir, Freundlich, Temkin and Dubinin-Radushkevich isotherms studies of equilibrium sorption of $\mathrm{Zn}^{2+}$ unto phosphoric acid modified rice husk. IOSR J. Appl. Chem. 3, 38-45.

[19] Temkin, M. and Pyzhev, V. (1940) Kinetics of Ammonia Synthesis on Promoted Iron Catalysts. Acta Physicochimica URSS, 12, 217-222.

[20] C. Aharoni, M. Ungarish. (1977). Kinetics of activated chemisorption. Part 2. Theoretical models. J. Chem. Soc. Faraday Trans., 73, pp. 456464

[21] Ananta, S., Saumen, Banerjee, Vijay, Veer. (2015). Adsorption Isotherm, Thermodynamic and Kinetic Study of Arsenic (III) on Iron Oxide Coated Granular Activated Charcoal. Int. Res. J. Environ. Sci. (1) 4 : 64-77

[22] Yadav SK, Dixit AK. (2015). Efficient Removal of Cr (VI) from Aqueous Solution onto Palm Trunk Charcoal: Kinetic and Equilibrium Studies. Chem. Sci. J. 6: 114.

[23] Günay, A., Arslankaya, E., Tosun, İ., (2007). Lead removal from aqueous solution by natural and pretreated clinoptilolite: Adsorption equilibrium and kinetics. J. Hazard. Mater. 146, 362-371

[24] Dubinin, M.M., Radushkevich, L.V., (1947). Equation of the characteristic curve of activated charcoal. Proc. Acad. Sci. Phys. Chem. Sect. USSR. 55, 331-333.

[25] Tchobanoglous, G., Burton, F.L., Stensel, H.D., (2003). Wastewater engineering: Treatment and reuse, 4th edition. Metcalf \& Eddy, McGraw-Hill Companies Inc, New York.

[26] Lagergren, S., (1898). Zurtheorie der sogenannten adsorption gelosterstoffe. KungligaSevenska Vetenskapasakademiens, Handlingar 24, 1-39.
[27] Ho, Y.S., Wang, C.C., (2004). Pseudo-isotherms for the sorption of cadmium ion onto tree fern, Process Biochem. 39 (6), 759-763.

[28] Ho, Y.S., (2004). Pseudo-isotherms using a second order kinetic expression constant, Adsorpt. J. Int. Adsorpt. Soc. 10 (2), 151-158.

[29] Wong, K. K., Lee, C. K., Low, K. S. and Haron, M. J., (2003). Removal of $\mathrm{Cu}$ and $\mathrm{Pb}$ by tartaric acid modified rice husk from aqueous solutions. Chemosphere, 50, 23-28.

[30] Ho, Y.S., (2006), Review of Second-order Models for adsorption systems, J. Hazard. Mater., 36, 681-689.

[31] Weber, J.W., Morris, J.C., (1963). Kinetics of adsorption oncarbon from solution. J. Sanitary Eng. Div., ASCE 89, 31-60.

[32] Chabani, B., Amrane, A. and Bensmaili, A. (2006) Kinetic modeling of the adsorption of nitrates by ion exchange resin. Chem. Eng. J., 125, 111117.

[33] Islam, M., Patel, R., (2009). Nitrate sorption by thermally activatedMg/Al chloride hydrotalcite-like compound. J. Hazard. Mater. 169, 524-531.

[34] Gupta, S. S. and K.G. Bhattacharyya, (2005). Interaction of metal ions with clays: A case study with Pb (II). Appl. Clay Sci., 30: 199-208.

[35] Nisaa S. (2011). Adsorpsi biru metilena pada kaolin dan nanokomposit kaolin TiO2 serta uji sifat fotokatalis. [skripsi]. Bogor: Fakultas Matematika dan Ilmu Pengetahuan Alam, Institut Pertanian Bogor.

[36] Armaroli T., Simon L. J., Digne M., Montanari T., Bevilacqua M. Valtchev V., Patarin J., Busca G. (20016). Effects of crystal size and Si/Al ratio on the surface properties of H-ZSM-5 zeolites. Appl. Catal A Gen. 306:78-84

[37] Mohamed, M., O.A. Fouad, A.A. Ismail, I.A. Ibrahim. (2005). Influence of crystallization times on the synthesis of nanosized ZSM-5, Mater. Lett. 59(27).

[38] Somani, O. G,. Anant L. Choudhari, Bandaru Sarva Rao, S.P. Mirajkar. (2006). Enhancement of crystallization rate by microwave radiation: Synthesis of ZSM-5. Mater. Chem. Phys. 82(3):538-545.

[39] Adamson, A.W., (1990), Physical chemistry of surface, 5th ed., John Willey \&. Sons, New York.

[40] Yahya, S. A., Musa, I. E., Amjad, H. E., and Gavin, M. W. (2008). Effect of solution $\mathrm{pH}$, ionic strength, and temperature on adsorption behavior of reactive dyes on activated carbon. Dyes Pigm., 77: 16-23.

[41] Ajemba, R.O. (2014). Assessing influence of hydrochloric acid leaching on structural changes and bleaching performance of Nigerian clay from Udi Optim. Isotherm Kinet. Stud., 27: 839-854.

[42] Gercel, O., Ozcan, A., Ozcan, A.S., and Gercel, H.F. (2007). Preparation of activated carbon from a renewable bio-plant of Euphorbia rigida by $\mathrm{H} 2 \mathrm{SO} 4$ activation and its adsorption behavior in aqueous solutions. Appl. Surf. Sci. 253: 4843-4852

[43] Wu, F.C., Tseng, R.I., and Jung, R.S. (2001). Kinetic modeling of liquidphase adsorption of reactive dyes and metal ions on chitosan. Water Res. 35: 613-618.

[44] Harni, Muhammad Rudy, Ani Iryani, Hilman Affandi. (2013) Pemanfaatan serbuk gergaji kayu jati (tectona grandis l.f.) sebagai adsorben logam timbal ( $p b)$. Program Studi Kimia, FMIPA Universitas Pakuan, Bogor.

[45] Venkata, S., Mohan, N., Rao, C., and Karthikeyan, J. (2002). Adsorptive removal of direct azo dye from aqueous phase onto coal based sorbents: a kinetic and mechanistic study. J. Hazard. Mater. 90: 189-204.

[46] Bello, O.S., Tan, T.S., and Ahmad, M.A. (2011). Utilization of cocoa pod husk for the removal of remazol black B reactive dye from aqueous solutions: Kinetic, equilibrium and thermodynamic studies. Asia-Pac. J. Chem. Eng. 7: 378-388.

[47] Tan, I.A.W., Ahmad, A.L., and Hameed, B.H. (2008). Adsorption of basic dye on high-surface-area activated carbon prepared from coconut husk: equilibrium, kinetic and thermodynamic studies. Desalination 225: 13-28. 